\title{
Desquamative interstitial pneumonitis in a healthy non-smoker: A rare diagnosis
}

\author{
Ryan R Kroll ${ }^{1}$, Diane A Flood MD FRCPC FCCP ${ }^{2}$, John Srigley MD FRCPC FRCPath ${ }^{2}$
}

RR Kroll, DA Flood, J Srigley. Desquamative interstitial pneumonitis in a healthy non-smoker: A rare diagnosis. Can Respir J 2014; 21(2):86-88.

\begin{abstract}
Desquamative interstitial pneumonitis is an interstitial lung disease most commonly associated with smoking. It causes respiratory symptoms including indolent cough and dyspnea. Characteristic findings on computed tomography include bilateral ground-glass opacities, septal thickening and preserved structure. Diagnosis is made by tissue sampling, which classically demonstrates alveolar macrophages, and thickened alveolar septa with an eosinophilic infiltrate lined with hyperplastic type II pneumocytes. Treatment is immune suppression with steroids or other agents, and avoiding the causal agent. The case reported describes a 27-year-old woman with no smoking history who worked in a potato chip factory, presenting with cough, dyspnea and dizziness. The patient had characteristic findings on imaging and was diagnosed via biopsy with desquamative interstitial pneumonitis. She improved clinically with reduced exposure and steroid therapy. While food production workers are at risk for respiratory illness, there are no reported cases of desquamative interstitial pneumonitis in this setting.
\end{abstract}

Key Words: Desquamative interstitial pneumonia; Interstitial pneumonitis; Occupational exposure; Potato chip factory

Learning objectives

- To recognize that clinical findings and imaging alone are insufficient for the diagnosis of desquamative interstitial pneumonitis (DIP); tissue sampling is required.

- To recognize that occupational history may be very important in someone with persistent respiratory symptoms.

CanMEDS Competency: Health Advocate

Pretest

- What histological findings are typical of DIP?

- What is the initial management for DIP?

\section{CASE PRESENTATION}

A 27-year-old woman presented to a walk-in clinic with an 18-month history of dry cough and was started on moxifloxacin and salbutamol. Within one month of initial presentation, she presented to the emergency department with worsening cough, exertional dyspnea and dizziness. Her medical history was notable only for wisdom teeth extraction, and there was no personal or family history of respiratory disease. She had no allergies or history of illicit drug use. She was a lifelong nonsmoker with no exposure to second-hand smoke, as well as no history of exposure to asbestos or tuberculosis. Recent travel included visits to Iceland and Scotland. The patient had been employed in a managerial role at a potato chip factory for 18 months but spent time on the production floor without a mask. Her temperature was $37.1^{\circ} \mathrm{C}$, with a heart rate of 98 beats $/ \mathrm{min}$, a blood pressure of $125 / 77 \mathrm{mmHg}$, a respiratory rate of 18 breaths/min and oxygen saturation of $98 \%$ on room air. Physical examination was unremarkable. Laboratory investigations included hemoglobin $119 \mathrm{~g} / \mathrm{L}$ (normal $115 \mathrm{~g} / \mathrm{L}$ to $155 \mathrm{~g} / \mathrm{L}$ ), leukocytes $5.3 \times 10^{9} / \mathrm{L}$ (normal $4.0 \times 10^{9} / \mathrm{L}$ to $11 \times 10^{9} / \mathrm{L}$ ) and platelets $197 \times 10^{9} / \mathrm{L}$

\section{Une pneumonite interstitielle desquamative chez un non-fumeur en santé : un diagnostic rare}

La pneumonite interstitielle desquamative est une maladie pulmonaire interstitielle qui s'associe surtout au tabagisme. Elle provoque des symptômes respiratoires, tels que la toux indolente et la dyspnée. À la tomodensitométrie, les observations caractéristiques incluent des opacités bilatérales en verre dépoli, un épaississement du septum et la préservation de la structure. Le diagnostic est posé par échantillonnage des tissus, qui démontre habituellement des macrophages alvéolaires et un épaississement du septum alvéolaire dont l'infiltrat éosinophile est recouvert de pneumocytes hyperplasiques de type II. Le traitement consiste à favoriser une immunosuppression par stéroïdes ou d'autres agents et à éviter l'agent causal. Les auteurs présentent le cas d'une femme de 27 ans sans antécédents de tabagisme, qui travaillait dans une usine de croustilles et qui a consulté en raison d'une toux, d'une dyspnée et d'étourdissements. Elle affichait les observations caractéristiques à l'imagerie, et la biopsie a révélé une pneumonite interstitielle desquamative. Son état s'est amélioré sur le plan clinique après une diminution de l'exposition et la stéroïdothérapie. Les travailleurs des usines de production alimentaire sont vulnérables aux maladies respiratoires, mais il n'existe aucun cas déclaré de pneumonite interstitielle desquamative dans ce contexte.

(normal $145 \times 10^{9} / \mathrm{L}$ to $400 \times 10^{9} / \mathrm{L}$ ). Electrolyte and creatinine levels were within the normal range. Her lactate dehydrogenase level was $251 \mathrm{U} / \mathrm{L}$ (normal $110 \mathrm{U} / \mathrm{L}$ to $215 \mathrm{U} / \mathrm{L}$ ) and erythrocyte sedimentation rate was $25 \mathrm{~mm} / \mathrm{h}$ (normal $0 \mathrm{~mm} / \mathrm{h}$ to $20 \mathrm{~mm} / \mathrm{h}$ ). Cultures were negative for fungi, tuberculosis and pathogenic bacteria. Rheumatoid factor, antinuclear antibodies, extractable nuclear antigens, angiotensinconverting enzyme and aspergillus testing were all negative. Hepatitis $\mathrm{C}$ testing was not performed due to the absence of risk factors.

Initial chest radiographs showed an ill-defined density in the lingula (Figures 1 and 2). Computed tomography (CT) scan of the chest without contrast revealed ground-glass opacities in all lobes and in all segments, but with a predominance of lower lobe involvement. Linear bibasilar reticular fibrosis was also noted. There was no lymphadenopathy or suspicious nodules, and all other structures appeared to be normal (Figures 3 and 4).

The patient was referred to a respirologist and pulmonary function tests (PFTs) were performed. The results were consistent with a restrictive defect (Table 1 ).

To make a definitive diagnosis, wedge resections of both the left upper and left lower lobes were obtained. The biopsies showed prominent accumulations of alveolar macrophages with a small number of eosinophils. The alveolar septa were mildly thickened by a chronic inflammatory cell infiltrate consisting of both lymphocytes and plasma cells, with the former predominating, and were lined by hyperplastic type II pneumocytes. There was no evidence of granulomatous inflammation, malignancy, fibroblastic foci or honeycombing. The pathological diagnosis was a DIP (Figures 5 and 6). Based on the clinical picture, the CT findings and the biopsy results, the patient was diagnosed with DIP. The patient was removed from the production floor environment, but did not clinically improve until she was started on prednisone $30 \mathrm{mg} / \mathrm{day}$. At the time of submission, the patient was

${ }^{1}$ Queen's University School of Medicine, Kingston; ${ }^{2}$ Trillium Health Partners, Credit Valley Hospital Site, Mississauga, Ontario

Correspondence: Mr Ryan R Kroll, Queen's University School of Medicine, 590 St Clements Avenue, Toronto, Ontario M5N 1 M6.

Telephone 613-539-8151, e-mail rkroll@qmed.ca 


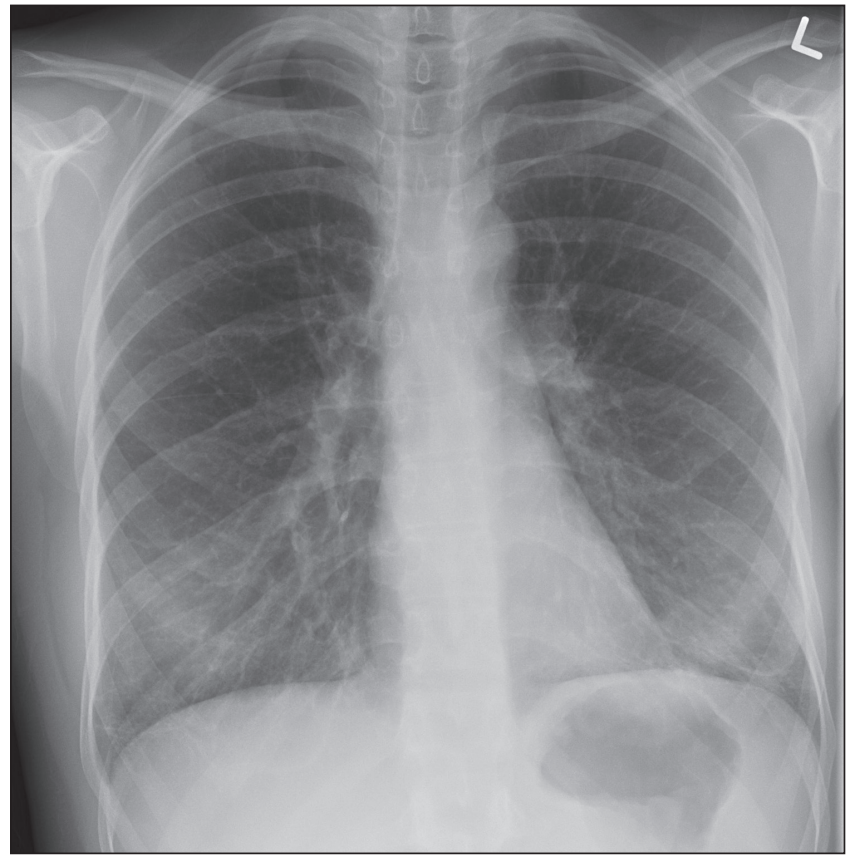

Figure 1) Chest radiograph, posterior-anterior view, demonstrating a lingular density

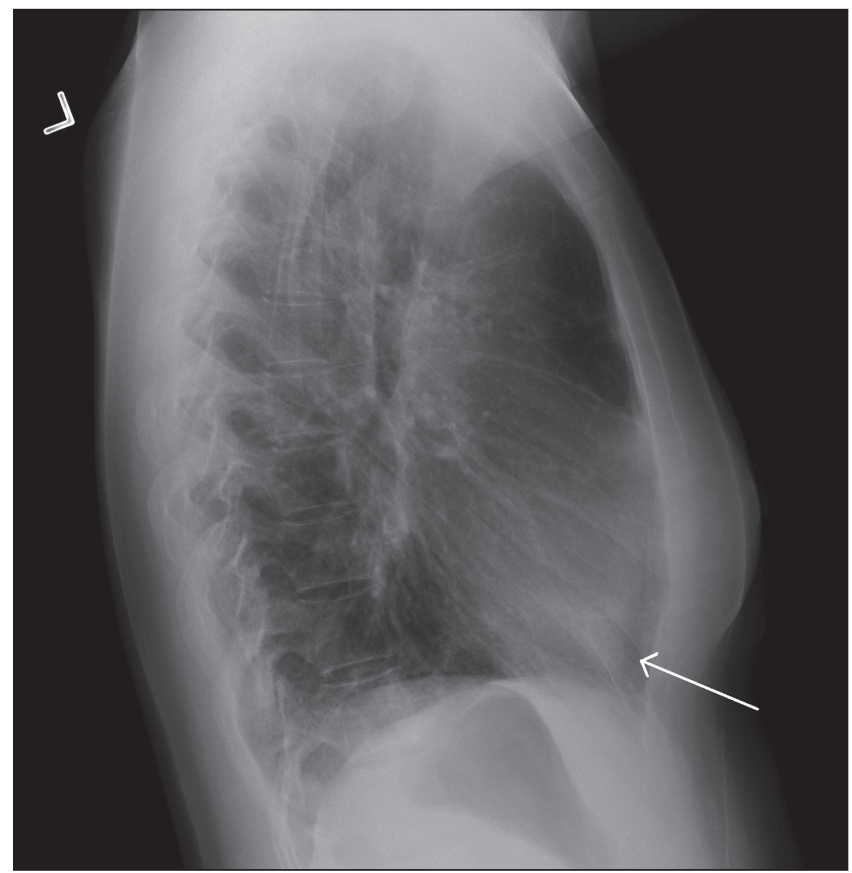

Figure 2) Chest radiograph. Lateral view demonstrating a lingular density (arrow)

being tapered off the prednisone; repeat PFTs have not yet been conducted.

\section{DISCUSSION}

DIP is a rare, serious, potentially fatal, inflammatory pulmonary disease first described in 1965 by Liebow et al (1). While DIP is most commonly found in tobacco smokers in their fourth and fifth decades of life, it is also associated with other entities including rheumatoid arthritis, use of sirolimus, nitrofurantoin, sulfasalazine and tocainide, cytomegalovirus, aspergillus exposure, hepatitis C, surfactant dysfunction in children, myeloid neoplasms, diesel fumes and marijuana smoking; it can also be idiopathic $(1,2)$. DIP has been reported in individuals with occupations that expose them to inorganic dusts and

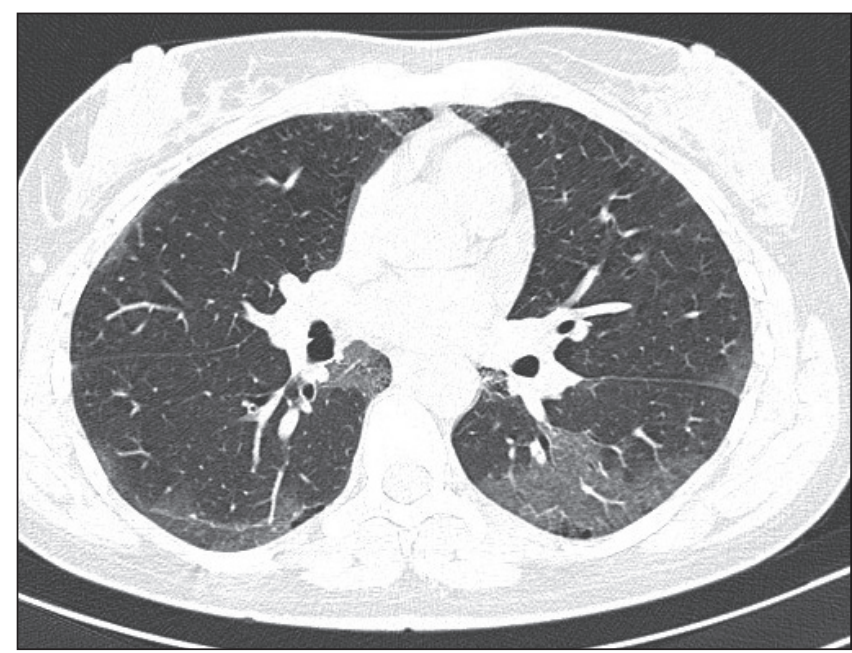

Figure 3) Chest computed tomography. Transverse view showing bilateral ground-glass opacities and alveolar septal thickening

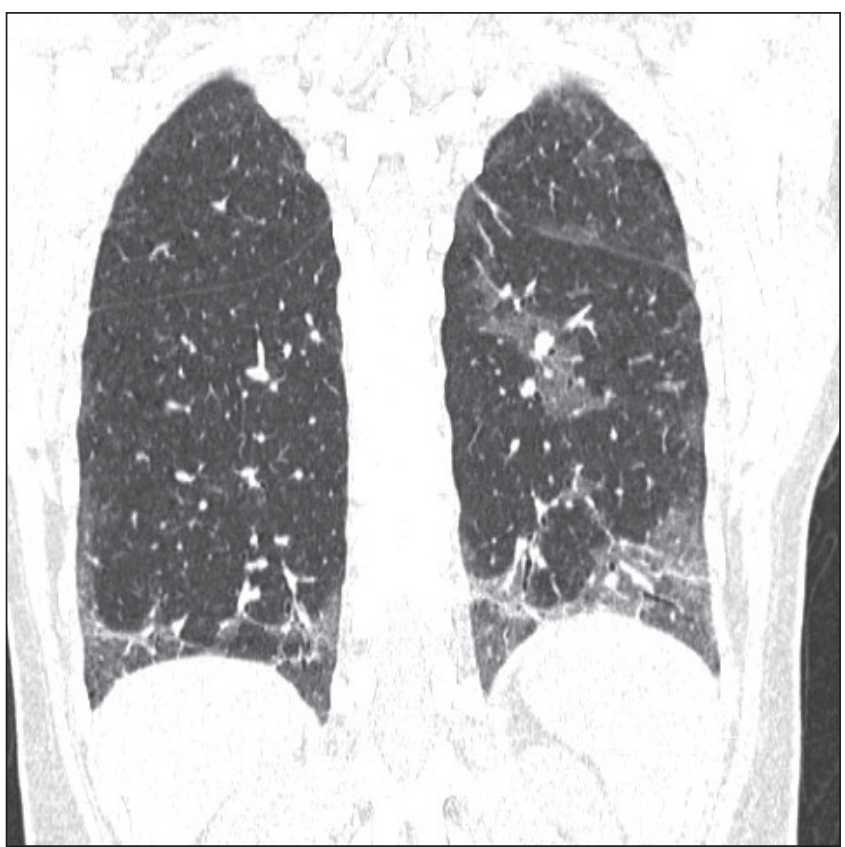

Figure 4) Chest computed tomography scan (coronal view) emphasizing bilateral ground-glass opacities in the lower lobes

fumes. These occupations are described by Benoît et al (3) and include tool grinding, textile manufacturing, arc polishing, tire manufacturing, arc welding and plastic machining.

Patients with DIP tend to present with insidious onset of nonspecific respiratory symptoms, including chronic cough that may be productive, chronic dyspnea and chest pain over the course of weeks to months $(2,4)$. Constitutional symptoms, such as weight loss and fatigue, have also been described (4). Signs on physical examination may or may not be present, and can include bibasilar end-inspiratory crackles and digital clubbing $(2,4)$.

Bloodwork findings vary in DIP, in some cases revealing eosinophilia, as well as elevated immunoglobulin (Ig) G and IgE levels, and increased erythrocyte sedimentation rate (5). PFTs in patients with DIP usually demonstrate either normal volumes or a restrictive pattern, with decreased forced vital capacity (FVC), decreased forced expiratory volume in $1 \mathrm{~s}\left(\mathrm{FEV}_{1}\right)$, a normal $\mathrm{FEV}_{1} / \mathrm{FVC}$ ratio and decreased diffusing capacity of the lung for carbon monoxide (4).

Findings on imaging in patients with DIP are variable and often inconclusive. Chest radiographs are insensitive in detecting DIP; they 


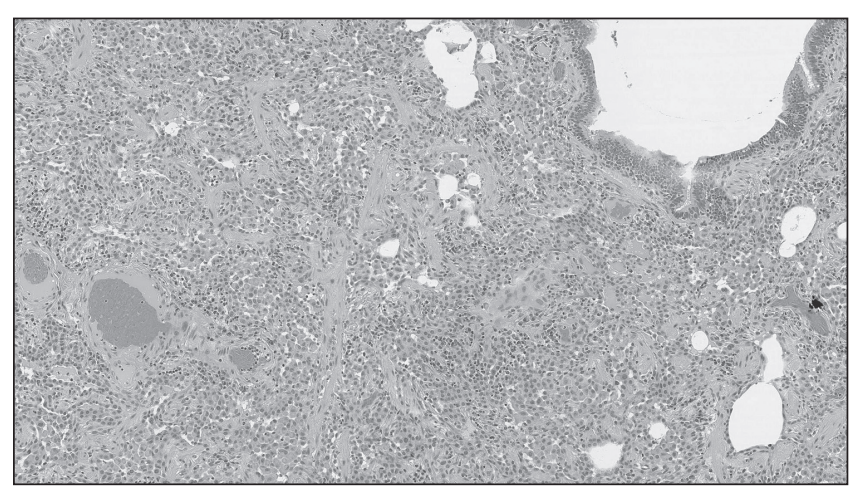

Figure 5) Low-power (10x) microscopy showing numerous alveoli packed with macrophages. A bronchiole is shown in the upper right

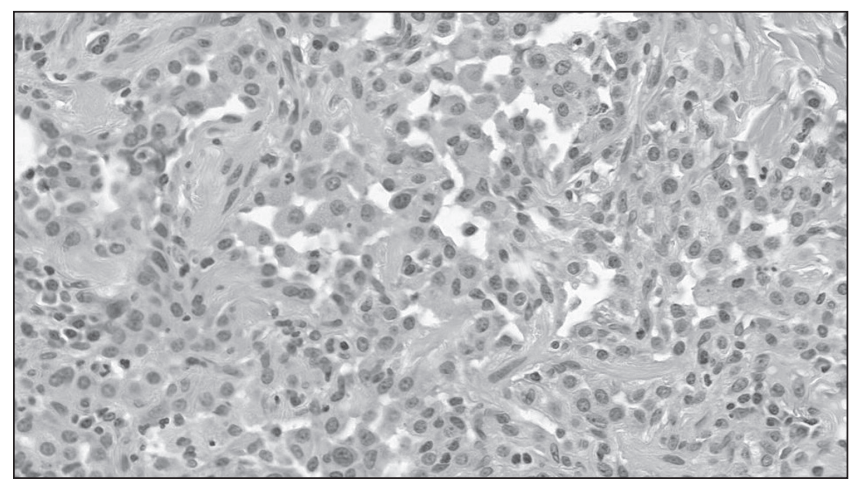

Figure 6) High-power (40x) microscopy showing alveoli filled with macrophages and a focally thickened interstitium

are normal in up to $22 \%$ of cases (4). Classically, the radiographic features of DIP are interstitial infiltrates or a patchy, ground-glass appearance that tends to occur peripherally and with a predilection for the lower lobes $(2,4)$. High-resolution CT scans of the chest also reveal variable features; the typical CT picture is one of diffuse, bilateral, symmetrical, predominately basilar, peripheral, ground-glass opacities and can also include alveolar septal thickening $(2,4)$. The lung architecture is typically preserved (6). Irregular linear opacities in the lower lobes and honeycombing can be appreciated in some cases $(4,5)$.

While imaging is useful in localizing lung involvement, tissue samples are required for diagnosis. Brochoalveolar lavage washings contain increased cell numbers with some combination of increased neutrophils, lymphocytes and eosinophils $(4,5)$. In patients who smoke, these macrophages have intracellular granules of light brown pigmentation (1). Biopsy results indicative of DIP include diffuse macrophage accumulation within the alveoli; macrophages frequently contain fine granules (4). The alveolar septa are thickened with chronic inflammatory cells and are lined with hyperplastic type II pneumocytes $(4,6)$. Lymphoid nodules and giant cells are sometimes seen (1). The relative preservation of lung architecture in tissue samples is debated $(5,6)$.

The management of DIP is not well defined in the literature. Smoking cessation is believed to be beneficial, although its exact impact is not fully understood $(1,2,4)$. Many patients with DIP are given systemic corticosteroids to decrease lung inflammation. Steroids have been shown to stabilize patients with DIP or slow the progression of fibrosis. However, steroids are not always effective in the long term, and patients can worsen once steroids are discontinued $(1,2)$. Other immunosuppressive agents have been used in some cases in addition to corticosteroids (4). Occupational exposure should be investigated and limited if it is considered to be a possible etiology (7).

The patient discussed was a known nonsmoker who was employed at a potato chip factory with no history of respiratory issues before her

\section{TABLE 1}

Selected pulmonary function tests

\begin{tabular}{|c|c|c|}
\hline & \multicolumn{2}{|c|}{ Prebronchodilator } \\
\hline & Actual & $\%$ predicted \\
\hline FVC, L & 2.68 & 70 \\
\hline $\mathrm{FEV}_{1}, \mathrm{~L}$ & 2.53 & 78 \\
\hline $\mathrm{FEV}_{1} / \mathrm{FVC}$ & 0.95 & - \\
\hline Total lung capacity, L & 3.68 & 66 \\
\hline DLco & $13.4 \mathrm{~mL} / \mathrm{mmHg} / \mathrm{min}$ & 49 \\
\hline
\end{tabular}

DLco Diffusing capacity of the lung for carbon monoxide; FEV ${ }_{1}$ Forced expiratory volume in $1 \mathrm{~s}$; FVC Forced vital capacity

employment at this site. While not linked to potato chip manufacturing, there are cases of food production workers developing respiratory conditions, such as bronchiolitis obliterans, following exposure to diacetyl, a compound used in popcorn flavouring $(7,8)$. A PubMed search using the keywords "desquamative interstitial pneumonia" or "desquamative interstitial pneumonitis" and "potato" revealed no reported cases of occupational DIP in this setting. The patient's respiratory function did not fully improve after reducing her exposure to the work environment, but did improve following steroid therapy. The identity of a causal agent remains unknown and an industrial hygienist has not assessed the workplace at the time of submission. Investigations into the association between DIP and other workers in similar working environments may suggest a possible occupational etiology.

\section{Post-test \\ - What histological findings are typical of DIP?}

Typical findings in DIP include pigmented alveolar macrophages, thickened alveolar septa, a chronic inflammatory infiltrate, as well as hyperplastic type II pneumocytes lining the alveoli. Lymphoid follicles and giant cells are sometimes seen.

- What is the initial management for DIP?

Systemic corticosteroid therapy and cessation of the irritant are the main components of initial treatment of DIP.

ACKNOWLEDGEMENTS: Dr Diane Flood was a consultant in managing the patient discussed in the case, provided all data and images used in this report, and reviewed/revised the manuscript. Ryan Kroll analyzed the health records for this patient and compiled the manuscript. Dr John Srigley provided the pathology information and images, and reviewed/ revised the manuscript. All authors approved of the final manuscript.

\section{REFERENCES}

1. Tazelaar HD, Wright JL, Churg A. Desquamative interstitial pneumonia. Histopathology 2011;58:509-16.

2. Ryu JH, Myers JL, Capizzi SA, et al. Desquamative interstitial pneumonia and respiratory bronchiolitis-associated interstitial lung disease. Chest 2005;127:178-84.

3. Benoît G, Wissler M-P, Vignaud J-M. Desquamative interstitial pneumonia: An analytic review with an emphasis on aetiology. Eur Respir Rev 2013;22:117-23.

4. Davies G, Wells AU, du Bois RM. Respiratory bronchiolitis associated with interstitial lung disease and desquamative interstitial pneumonia. Clin Chest Med 2004;25:717-26.

5. Kawabata Y, Takemura T, Hebisawa A, et al. Eosinophilia in bronchoalveolar lavage fluid and architectural destruction are features of desquamative interstitial pneumonia. Histopathology 2008;52:194-202.

6. Hartman TE, Primack SL, Eun-Young K, et al. Disease progression in usual interstitial pneumonia compared with desquamative interstitial pneumonia: Assessment with serial CT. Chest 1996;100:378-82.

7. Kanwal R. Severe occupational lung disease from exposure to flavoring chemicals. Am Fam Phys 2009;79:87.

8. Hendrick DJ. "Popcorn worker's lung" in Britain in a man making potato crisp flavouring. Thorax 2008;63:267-8. 


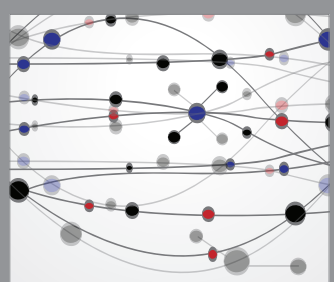

The Scientific World Journal
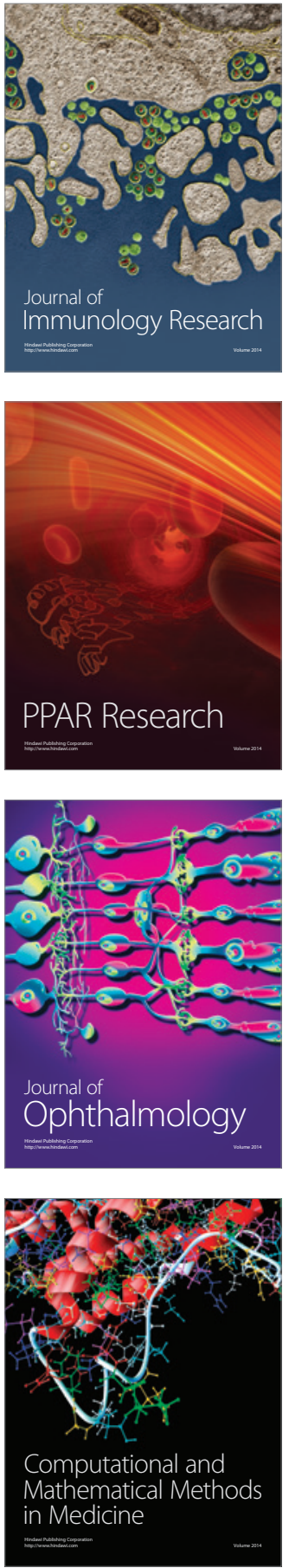

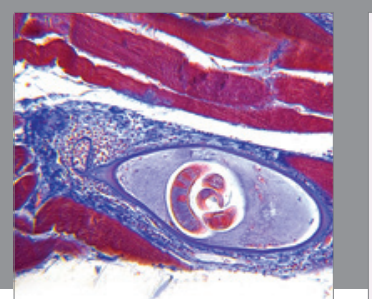

Gastroenterology Research and Practice

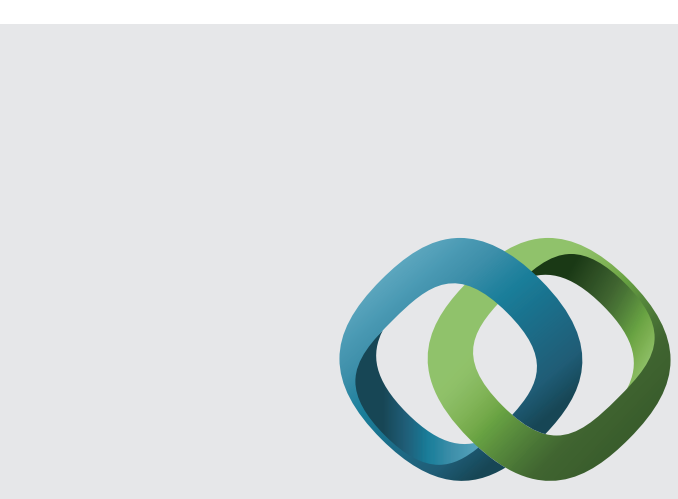

\section{Hindawi}

Submit your manuscripts at

http://www.hindawi.com
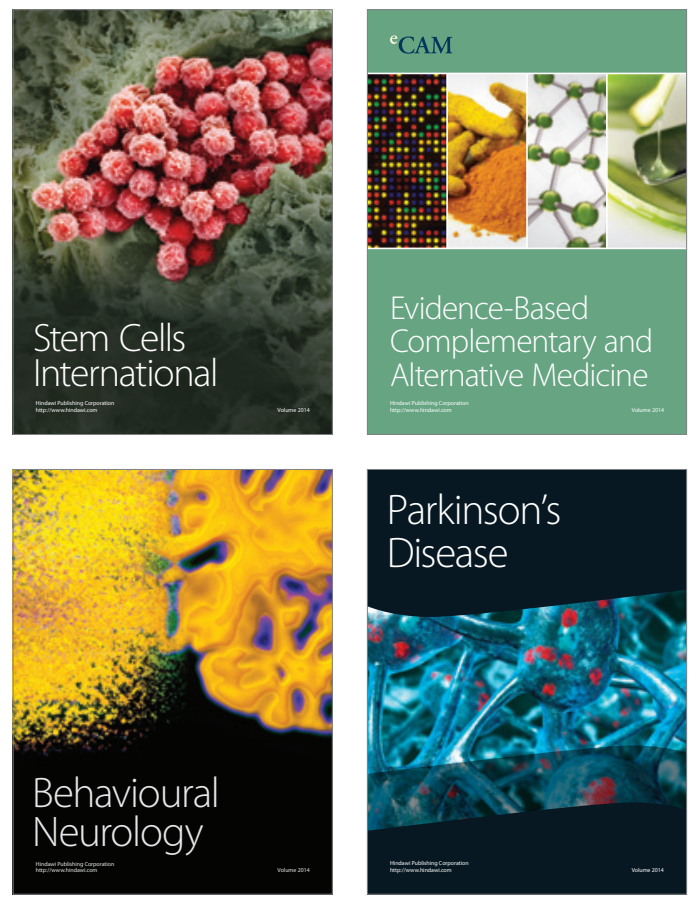
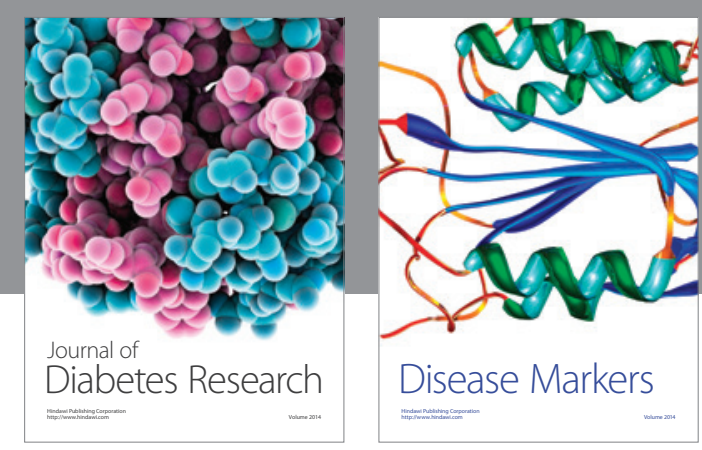

Disease Markers
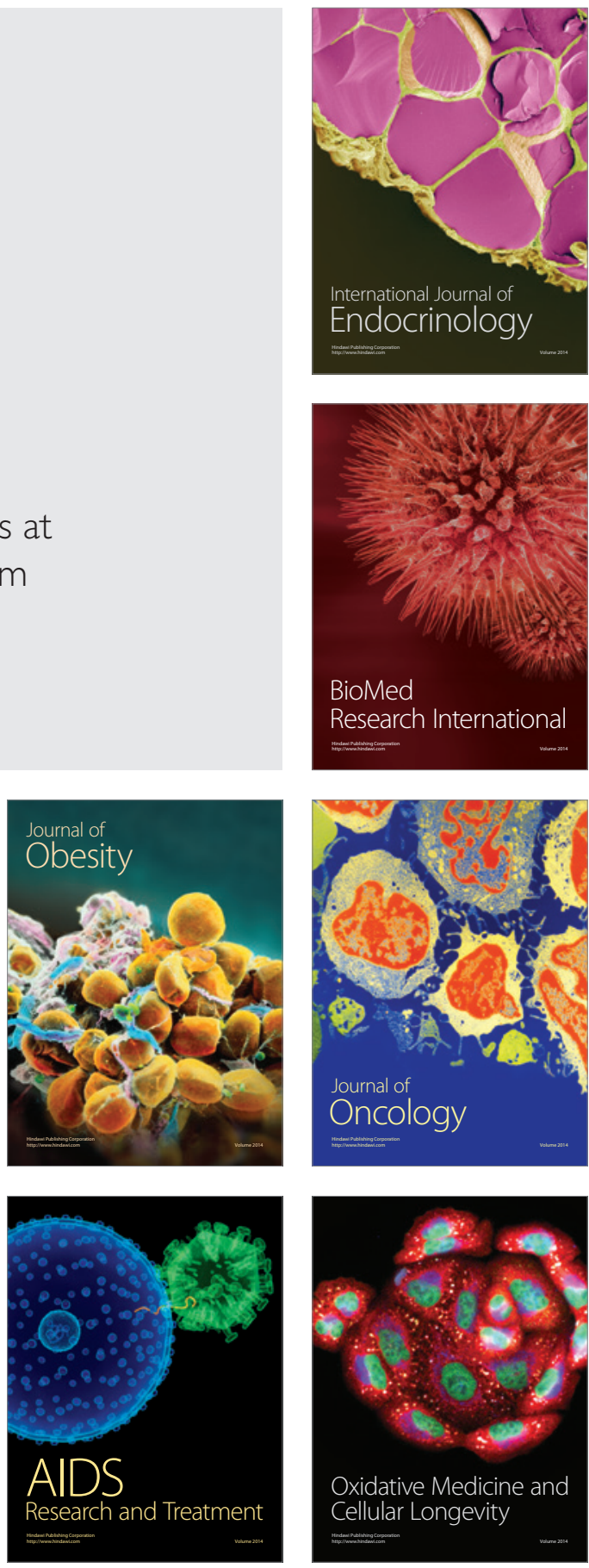